\title{
Abstract \\ Accuracy of visual estimation of blood loss in pregnancy by using simulated case scenarios
}

Ekanayake E M S B ${ }^{1}$, Abeykoon $\mathbf{W}^{1}$, Casather $\mathrm{D} \mathrm{M}^{1}$, Fahim S M $^{1}$, Chandrasiri $\mathrm{D}^{1}$

${ }^{1}$ Teaching Hospital, Kandy, Sri Lanka

Key words: Obstetric haemorrhage, visual estimation

\begin{abstract}
Introduction
Major obstetric haemorrhage continues to be one of the life threatening problems in pregnancy around the world as it accounts for $31 \%$ of overall maternal deaths.

Objective

This observational study is to determine discrepancy between actual blood loss $(A B L)$ and estimated blood loss (EBL).

Methods

Twelve simulated case scenarios with known measured amounts of blood were created using expired packed red cell and common surgical materials, and assessed by the participants including doctors, medical students, nurses and midwives at the Teaching Hospital, Kandy

Results

There were 120 participants. 30\% doctors with $66.7 \%$ nurses with mean years of clinical experience at 14.25 years (mode $-5 y$ ) and experience to maternity unit at 6.54 years (mode $-5 y$ ). Visual estimations were especially inaccurate with smaller volumes, which could be overestimated by up to $120 \%$ : surgical towel soaked with $40 \mathrm{~mL}$ of blood $(+75 \%)$ and soaked with $60 \mathrm{~mL}$ of blood $(+33 \%)$, surgical swab soaked with $15 \mathrm{~mL}$ of blood $(+33 \%)$, surgical gauze 18 inch with $100 \mathrm{~mL}$ of blood $(+120 \%)$.

Blood in a container was more accurately estimated: $300 \mathrm{~mL}$ of blood in a kidney tray $(0 \%), 500 \mathrm{~mL}$ of blood in a bowl $(0 \%)$

Significant underestimation of the $\mathrm{ABL}$ occurred in 3 of the 12 stations: blood spill on the floor of $500 \mathrm{~mL}(20 \%), 1000 \mathrm{~mL}(40 \%), 2000 \mathrm{~mL}(25 \%)$.

There was no significant difference in clinical experience and type of exposure in most stations.

Conclusion

Health care providers tend to overestimate at lower blood volumes $(<500 \mathrm{ml})$ but underestimate at higher blood volumes $(>500 \mathrm{ml})$. Further training and monitoring in visual estimation skills are necessary in order to prevent associated maternal mortality and morbidity.
\end{abstract}

